Alves, P.A.G.; Oliveira, M.T.C, Ecoturismo e Educação Ambiental no cerrado paulista: diagnóstico das condições de uso público do Parque Estadual do Juquery, Caieiras e Franco da Rocha (SP). Anais do VIII Congresso Nacional de Ecoturismo e do IV Encontro Interdisciplinar de Ecoturismo em Unidades de Conservação. Revista Brasileira de Ecoturismo, São Paulo, v.4, n.4, 2011, p. 583.

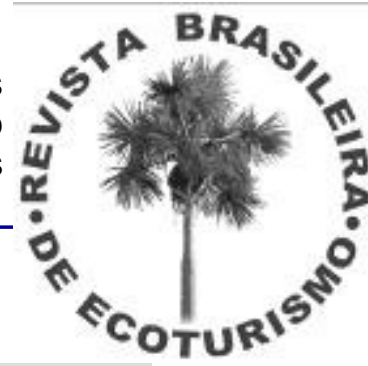

\title{
ECOTURISMO E EDUCAÇÃO AMBIENTAL NO CERRADO PAULISTA: DIAGNÓSTICO DAS CONDIÇÕES DE USO PÚBLICO DO PARQUE ESTADUAL DO JUQUERY, CAIEIRAS E FRANCO DA ROCHA (SP)
}

\author{
Patricia Adalgisa Gobitti Alves*, Marcelo Texeira Cesar de Oliveira* \\ *Instituto Ipá Ti-uá de Meio Ambiente, Cultura e Sociedade \\ E-mails: patadalgisa_biologia@yahoo.com.br, marcelotco@ipatiua.com.br
}

O Cerrado é um dos biomas mais destruídos pela ação da agricultura mecanizada para plantio de soja, algodão e milho em várias regiões do Brasil, tendo reduzido, significativamente, a sua área original. Em São Paulo, representado por manchas em diversas regiões do Estado, está hoje preservado em algumas Unidades de Conservação (UC)s públicas como os Parques Estaduais das Furnas do Bom Jesus, de Porto Ferreira, Vassununga e na Floresta Estadual de Assis, todos sob a responsabilidade da Fundação para a Conservação e a Produção Florestal do Estado de São Paulo. O Parque Estadual do Juquery (PEJ), que apresenta o último fragmento de cerrado da Região Metropolitana de São Paulo (RMSP), está situado nos municípios de Franco da Rocha e Caieiras. O Decreto Estadual no 36.859/93 garantiu a proteção de uma área total de 2.058,09 ha, situada nas coordenadas $23^{\circ} 21^{\prime} \mathrm{S}$ e $46^{\circ} 42^{\prime} \mathrm{W}$. O acesso ao PEJ pode ser feito pela rodovia Pref. Luiz Salomão Chamma (SP-023). O presente trabalho analisou o potencial para a atividade de ecoturismo e educação ambiental, considerando a demanda potencial de público, as condições atuais das instalações, as trilhas, a paisagem e o atendimento ao visitante. Foram realizadas visitas entre março de 2009 a dezembro de 2010 registrando com fotos e anotações de campo. A pesquisa foi complementada através de bibliografia, documentos e da legislação, além da internet . O acesso ao PEJ é fácil e a proximidade a cidade de São Paulo, o maior mercado emissivo brasileiro em ecoturismo, tornam a área uma região potencial para visitações curtas aos finais de semana e feriados prolongados. Na área existe um Núcleo de Educação Ambiental (NEA) com museu compostos de exemplares de flora e de animais locais taxidermizados, moldes de pegadas em gesso, painéis explicativos, rochas e vitrine do bioma do cerrado. O auditório tem equipamentos multimídia e capacidade de 60 pessoas. Apenas dois banheiros para o público em toda área. Lixeiras de reciclados foram encontrados em apenas uma área do PEJ. Não existe venda de alimentos mas quiosques para piqueniques. Não há estacionamento planejado e nem nenhuma estrutura para acesso de portadores de deficiência. Possui seis trilhas abertas ao público, uma delas levando a uma torre de observação. Placar tem informação de tamanho do percurso e o grau de dificuldade. Não há avisos ou e recomendações sobre riscos. É obrigatória para a trilha dos Pitus. O PEJ recebe escolares com agendamento prévio. Não foi identificado uma programa de formação de monitores e houve carência de informações sobre o ambiente. Apesar das condições encontradas, há freqüência alta de visitas escolares. Por ano aproximadamente 15.000 alunos de escolas públicas e privadas visitam PEJ. Nos finais de semana praticamente não há visitantes apesar de estar na RMSP, por exemplo, se comparado ao vizinho P.E. Cantareira que recebe um grande volume de pessoas. A área tem um bom uso para estudos do meio, mas não desenvolveu seu potencial para o Ecoturismo. A vista aberta atende mais a população para lazer que não freqüentam trilhas.

Palavras-chave: Juquery; Cerrado; Ecoturismo. 